\title{
DBU-promoted carboxylative cyclization of o-hydroxy- and o-acetamidoacetophenone
}

\author{
Wen-Zhen Zhang ${ }^{*}$, Si Liu and Xiao-Bing Lu
}

\author{
Letter \\ Address: \\ State Key Laboratory of Fine Chemicals, Dalian University of \\ Technology, Dalian, 116024, P. R. China \\ Email: \\ Wen-Zhen Zhang* - zhangwz@dlut.edu.cn \\ ${ }^{*}$ Corresponding author \\ Keywords: \\ acyl migration; carbon dioxide; carboxylation; cyclization; \\ condensation
}

\author{
Beilstein J. Org. Chem. 2015, 11, 906-912. \\ doi:10.3762/bjoc.11.102 \\ Received: 06 February 2015 \\ Accepted: 18 May 2015 \\ Published: 29 May 2015 \\ This article is part of the Thematic Series " $\mathrm{CO}_{2}$ Chemistry". \\ Guest Editor: W. Leitner \\ () 2015 Zhang et al; licensee Beilstein-Institut. \\ License and terms: see end of document.
}

\begin{abstract}
The carboxylative cyclization of $o$-hydroxy- and $o$-acetamidoacetophenone with carbon dioxide promoted by the organic base 1,8 diazabicycloundec-7-ene (DBU) is reported. This reaction provides convenient access to the biologically important compounds 4-hydroxy-2H-chromen-2-one and 4-hydroxy-2 $(1 H)$-quinolinone in moderate to good yields using carbon dioxide as the carboxylation reagent. An acyl migration from nitrogen to carbon is observed in the reaction of $o$-acetamidoacetophenone.
\end{abstract}

\section{Introduction}

4-Hydroxy-2H-chromen-2-ones and 4-hydroxy-2(1H)-quinolinones are key structural subunits found in many natural products [1], commercial drugs [2,3] and pharmacologically potent compounds (Figure 1) [4,5]. Warfarin, for example, is an anticoagulant widely used to prevent thrombosis [2]; Novobiocin has long been established as an aminocoumarin antibiotic [3] Recent studies revealed that the anticoagulant Dicumarol is able to inhibit the growth of pancreatic cancer [4]. Roquinimex was reported as an antineoplastic agent [5]. Traditional methods for accessing these compounds rely heavily on cyclization reactions using diethyl carbonate in the presence of inorganic bases $[6,7]$ or Friedel-Crafts reactions using strong and corrosive acids [8]. In terms of availability and toxicity of the starting materials, environmental benignity and economical concerns, the development of an alternative method for the synthesis of these compounds using carbon dioxide as the carboxylation reagent [9-16] is highly desirable.

It was previously reported that the $\alpha \mathrm{C}-\mathrm{H}$ bond in aromatic ketones readily undergoes a carboxylation reaction with carbon dioxide in the presence of a suitable base, producing $\beta$-ketocarboxylic acids [17-20]. Given that $o$-hydroxy- or $o$-acetamidoacetophenone is used as the starting material to react with carbon dioxide, the intramolecular carboxylative cyclization might provide a convenient access to 4-hydroxy- $2 \mathrm{H}$ chromen-2-one and 4-hydroxy-2(1H)-quinolinone. Indeed, Da Re and Sandri reported in 1960 that $o$-hydroxyacetophenone derivatives react with carbon dioxide $(4 \mathrm{MPa})$ in the presence of 
<smiles>CC(=O)CC(c1ccccc1)c1c(O)c2ccccc2oc1=O</smiles>

Warfarin<smiles>O=c1oc2ccccc2c(O)c1Cc1c(O)c2ccccc2oc1=O</smiles>

Dicoumarol<smiles>COC1C(OC(N)=O)C(O)C(Oc2ccc3c(O)c(NC(=O)c4ccc(O)c(CC=C(C)C)c4)c(=O)oc3c2C)CC1(C)C</smiles>

Novobiocin

Roquinimex

Figure 1: Selected examples for biologically active 4-hydroxy-2H-chromen-2-one and 4-hydroxy-2(1H)-quinolinone compounds.

3 equivalents of potassium carbonate at $130-170{ }^{\circ} \mathrm{C}$, yielding 4-hydroxy-2H-chromen-2-ones in moderate yields [21]. From the viewpoints of solubility, efficiency, and ease of recovery and reuse, the use of an organic base rather than potassium carbonate in this reaction would be more promising. DBU and MTBD were previously reported as suitable bases to promote the carboxylation of $\alpha-\mathrm{C}-\mathrm{H}$ bonds in aromatic ketones with carbon dioxide [17-20]. In extension of our continuous efforts in developing catalytic transformations of carbon dioxide into value-added fine chemicals $[20,22,23]$, we report herein the DBU-promoted carboxylative cyclization of $o$-hydroxy- and $o$-acetamidoacetophenones with carbon dioxide to give 4-hydroxy-2H-chromen-2-ones and 4-hydroxy-2(1H)-quinolinones, respectively, in moderate to good yields under mild reaction conditions. An acyl migration from the nitrogen to carbon is observed in the reaction of $o$-acetamidoacetophenone.

\section{Results and Discussion}

We started our investigation with the carboxylative cyclization of $o$-hydroxypropiophenone (1a) with carbon dioxide to identify the optimal organic base and reaction conditions (Table 1). The use of potassium carbonate as base in DMF at $100{ }^{\circ} \mathrm{C}$ gave

Table 1: Optimization of the reaction conditions. ${ }^{a}$

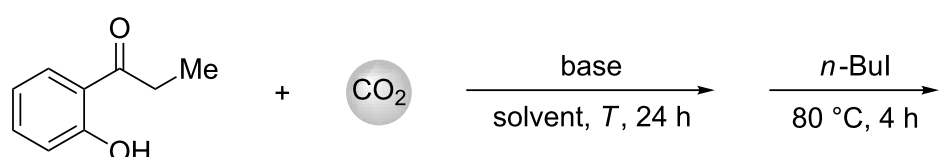

$1 \mathrm{a}$<smiles>CCCCOc1c(C)c(=O)oc2ccccc12</smiles>

2a

\begin{tabular}{|c|c|c|c|c|c|}
\hline Entry & Base & Solvent & $T /{ }^{\circ} \mathrm{C}$ & $p\left(\mathrm{CO}_{2}\right) / \mathrm{MPa}$ & Yield $/ \%$ b \\
\hline 1 & $\mathrm{~K}_{2} \mathrm{CO}_{3}$ & DMF & 100 & 3 & 29 \\
\hline 2 & DBU & DMF & 100 & 3 & 49 \\
\hline 3 & MTBD & DMF & 100 & 3 & 65 \\
\hline 4 & MTBD & DMSO & 100 & 3 & 68 \\
\hline 5 & DBU & DMSO & 100 & 3 & 75 \\
\hline 6 & DBU & DMAc & 100 & 3 & 32 \\
\hline 7 & DBU & THF & 100 & 3 & 10 \\
\hline 8 & DBU & DMSO & 80 & 3 & 87 \\
\hline 9 & DBU & DMSO & 60 & 3 & 65 \\
\hline 10 & DBU & DMSO & 80 & 2 & 53 \\
\hline 11 & DBU & DMSO & 80 & 0.1 & $<1$ \\
\hline
\end{tabular}

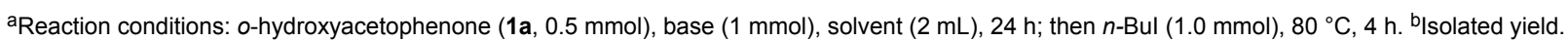


$29 \%$ yield of product 2 a (Table 1, entry 1 ). When DBU and MTBD were used in this reaction instead of potassium carbonate, a significantly increased yield of 2a was obtained (Table 1, entries 2 and 3). When switching the solvent to DMSO, further increased yields were obtained, whereby DBU showed a higher efficiency than MTBD (Table 1, entries 4 and 5). Other solvents such as DMAc and THF gave dramatically decreased yields (Table 1, entries 6 and 7). Unexpectedly, we found that a decrease of temperature from $100{ }^{\circ} \mathrm{C}$ to $80{ }^{\circ} \mathrm{C}$ in DMSO led to a higher yield (87\%) of $\mathbf{2 a}$ (Table 1, entry 8 ). The reaction was found to be sensitive to the carbon dioxide pres- sure and performing the reaction at a lower pressure gave a distinctly decreased yield (Table 1 , entry 10 ). When the reaction was conducted under atmospheric carbon dioxide, no carboxylative cyclization product was obtained (Table 1, entry 11). Therefore, the optimal reaction conditions were established as following: 2.0 equiv DBU as base, 3.0 MPa of carbon dioxide, DMSO as solvent at $80{ }^{\circ} \mathrm{C}$ for $24 \mathrm{~h}$.

Under the optimal reaction conditions, the substrate scope was then investigated (Table 2). Compared with $o$-hydroxypropiophenone, $o$-hydroxyacetophenone gave a slightly lower yield of

Table 2: Carboxylative cyclization of various o-hydroxyacetophenones with carbon dioxide. ${ }^{\text {a }}$

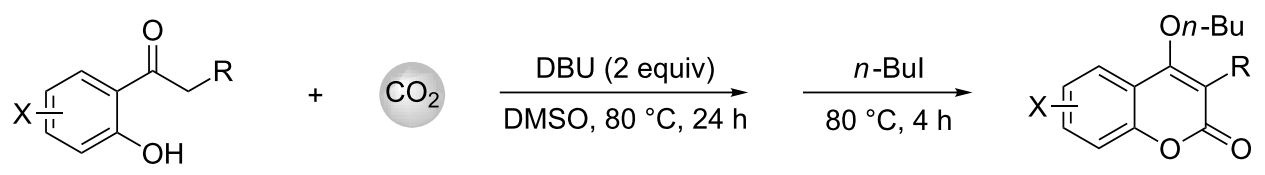

2

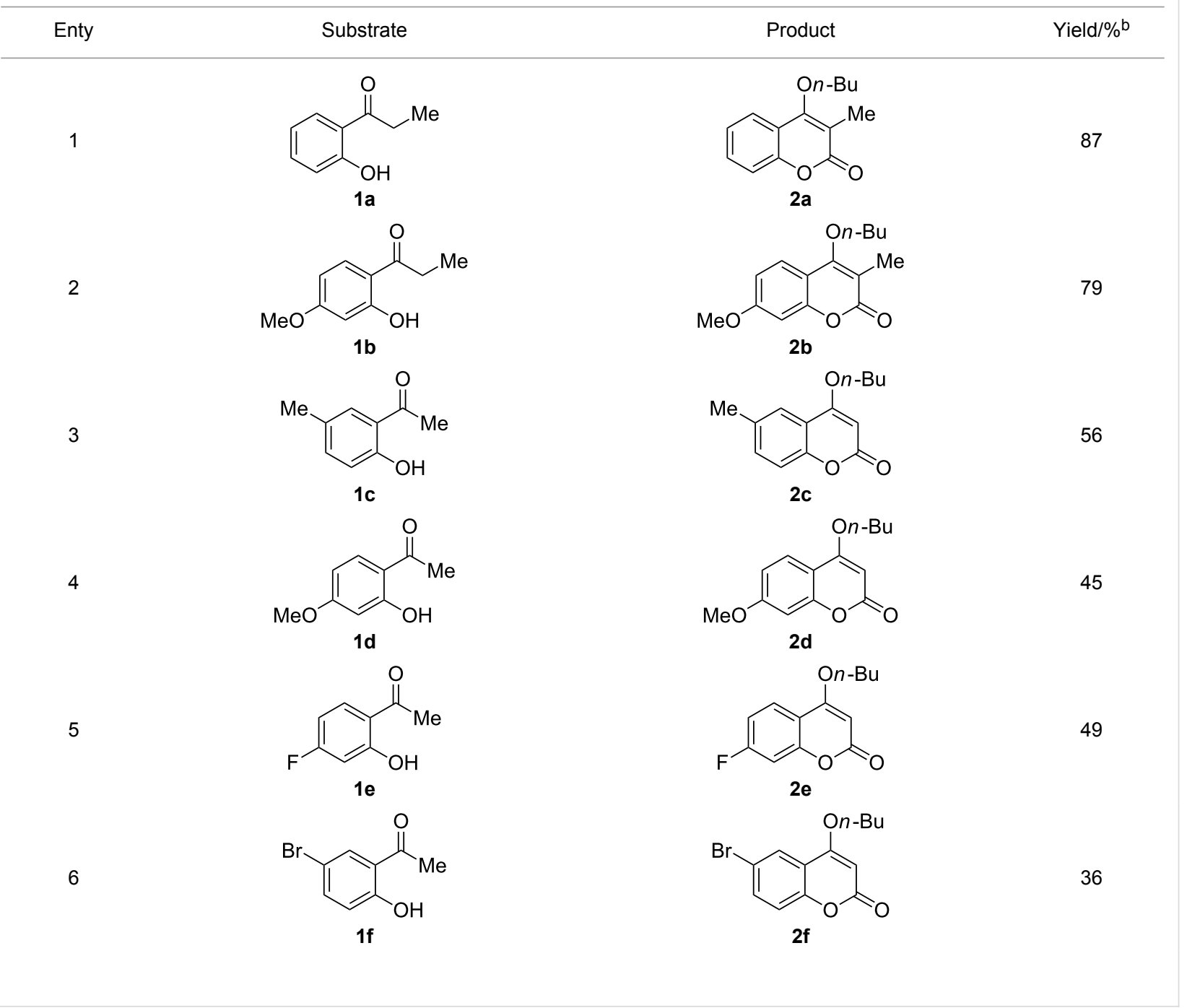


Table 2: Carboxylative cyclization of various o-hydroxyacetophenones with carbon dioxide. ${ }^{\text {a }}$ (continued)

7<smiles>CC(=O)c1ccc(C#Cc2ccc(C(C)(C)C)cc2)cc1O</smiles>

19

8<smiles>CC(=O)c1c(O)ccc2ccccc12</smiles>

$1 \mathrm{~h}$<smiles>CCCCOc1cc(=O)oc2cc(C#Cc3ccc(C(C)(C)C)cc3)ccc12</smiles>

$2 \mathrm{~g}$<smiles>CCCOc1cc(=O)oc2ccc3ccccc3c12</smiles>

2h

aReaction conditions: o-hydroxyacetophenone (1) $(0.5 \mathrm{mmol}), \mathrm{DBU}(1.0 \mathrm{mmol}), \mathrm{CO}_{2}(3.0 \mathrm{MPa}), \mathrm{DMSO}(2 \mathrm{~mL}), 80^{\circ} \mathrm{C}, 24 \mathrm{~h}$; then $n$-Bul $(1.0 \mathrm{mmol})$, $80^{\circ} \mathrm{C}, 4$ h. ' Isolated yield.

the $2 H$-chromen-2-one product (Table 2, entries 2 and 4 ). $o$-Hydroxyacetophenone bearing electron-donating alkyl and ether groups, or electron-withdrawing fluoro and bromo groups undergoes the carboxylative cyclization reaction smoothly, affording the corresponding 4-butoxy- $2 \mathrm{H}$-chromen-2-ones $\mathbf{2 b}-\mathbf{2 f}$ in moderate to good yields (Table 2, entries 2-6). The bromo group in product $\mathbf{2} \mathbf{f}$ and the alkyne group in product $\mathbf{2 g}$ offer opportunities for further functionalization of these $2 \mathrm{H}$-chromen-2-ones using well-established methods [24]
(Table 2, entries 6 and 7). 2-Hydroxy-1-acetylnaphthalene (1h) participates in the carboxylative cyclization reaction to furnish the tricyclic product $\mathbf{2 h}$ in moderate yield (Table 2, entry 8 ).

With the successful DBU-promoted carboxylative cyclization of $o$-hydroxyacetophenone at hand, we then extended this strategy to $o$-acetamidoacetophenone to synthesize 4-hydroxy-2(1H)quinolinone (Table 3). Using 4 equivalents DBU as base in $\mathrm{DMSO}$ at $80^{\circ} \mathrm{C}, o$-acetamidoacetophenone (3a) underwent the

Table 3: Carboxylative cyclization of various o-acetamidoacetophenones with carbon dioxide. ${ }^{a}$

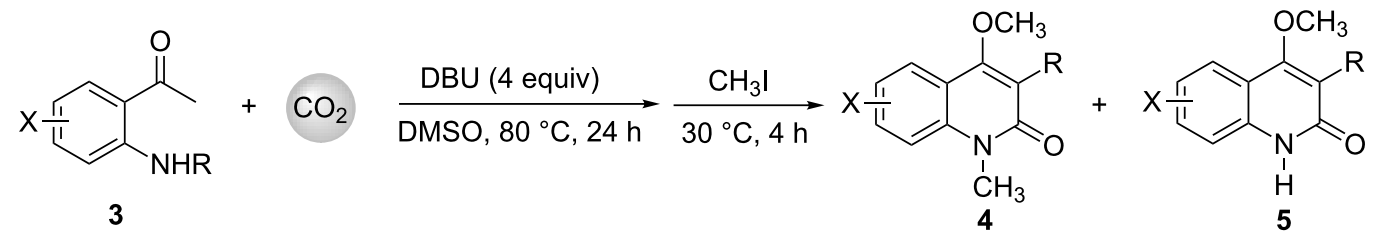

Entry


Table 3: Carboxylative cyclization of various o-acetamidoacetophenones with carbon dioxide. ${ }^{\text {a }}$ (continued)

3

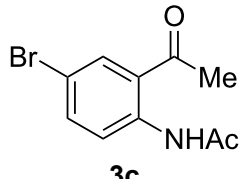

3c<smiles>CC(=O)c1ccccc1NC(=O)c1ccccc1</smiles>

$3 d$

5

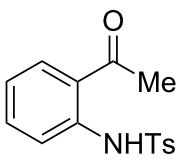<smiles>COc1c(C(C)(C)C)c(=O)n(C)c2ccc(Br)cc12</smiles>

4c<smiles>COc1c(Br)c(=O)n(C(C)(Cl)Cl)c2ccccc12</smiles>

4d<smiles>[3H]c1c(OC)c2ccccc2n(C)c1=O</smiles>

$4 e$<smiles>COc1c(C)c(=O)[nH]c2ccc(Br)cc12</smiles>

$5 c$<smiles>COc1c(Br)c(=O)n([13CH3])c2ccccc12</smiles>

$<1$<smiles>[3H]c1c(OC)c2ccccc2[nH]c1=O</smiles>

aReaction conditions: o-acetamidoacetophenone (3,0.5 mmol), DBU $(2.0 \mathrm{mmol}), \mathrm{CO}_{2}(3.0 \mathrm{MPa}), \mathrm{DMSO}(2 \mathrm{~mL}), 80^{\circ} \mathrm{C}, 24 \mathrm{~h}$; then $\mathrm{Mel}(2.0 \mathrm{mmol})$, $30{ }^{\circ} \mathrm{C}, 4 \mathrm{~h}$. ${ }^{\mathrm{b}}$ Isolated yield of separated products.

carboxylative cyclization reaction to provide 3-acetyl-4methoxy-2(1H)-quinolinones $\mathbf{4 a}$ and $\mathbf{5 a}$ (Table 3, entry 1$)$. Noteworthy, the acyl group was no longer bound to nitrogen in the product, which implies that a nitrogen to carbon acyl migration occurred during the reaction. The derivatization reaction using iodide compounds at higher temperature led to complex product mixtures. $o$-Acetamidoacetophenone substrates containing methoxy (3b) and bromo (3c) groups also reacted smoothly to afford the corresponding products (Table 3 , entries
2 and 3). The reactions using benzamido- (3d) and $p$-toluenesulfonamido- (3e) acetophenone gave complex mixtures and no carboxylative cyclization product was observed (Table 3, entries 4 and 5).

A likely mechanism for the carboxylative cyclization of $o$-acetamidoacetophenone with carbon dioxide is proposed as shown in Scheme 1. The reaction can evolve along two pathways: in path $\mathbf{A}$, deprotonation of $o$-acetamidoacetophenone by

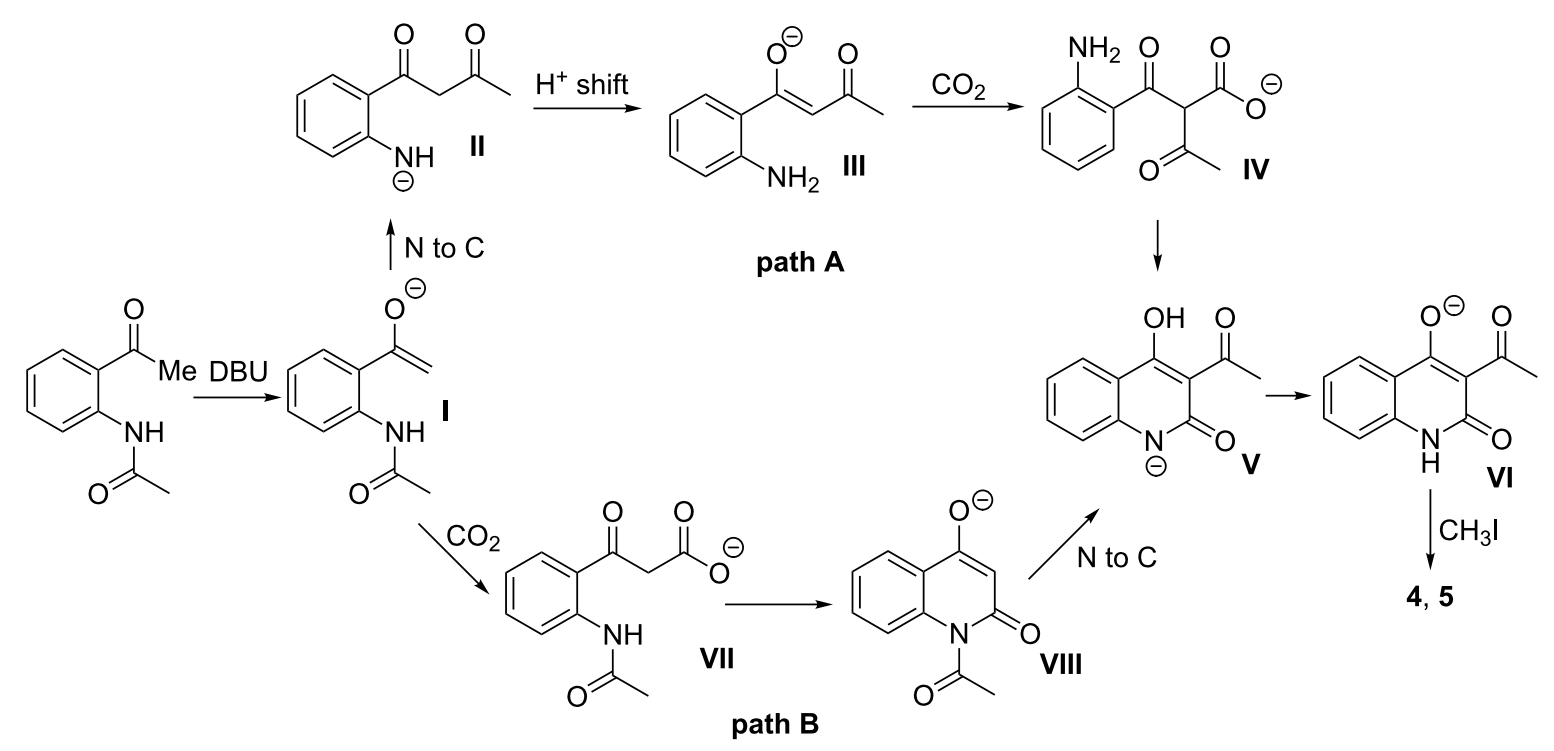

Scheme 1: Possible mechanism for the carboxylative cyclization of o-acetamidoacetophenone. 
DBU gives enolate $\mathbf{I}$, which undergoes an acyl migration from nitrogen to carbon $[25,26]$ similar to the Baker-Venkataraman $\mathrm{O}$ to $\mathrm{C}$ acyl migration [27]. After a proton shift from the enol to nitrogen, the resultant intermediate III is carboxylated with carbon dioxide in the presence of DBU to afford intermediate IV, which subsequently undergoes a cyclization reaction to give $\mathbf{V}$. The product is obtained after derivatization with methyl iodide. Also, path $\mathbf{B}$ in which the $\mathrm{N}$ to $\mathrm{C}$ acyl migration occurs after the carboxylative cyclization cannot be excluded.

We also conducted a cross experiment as shown in Scheme 2. When compounds $\mathbf{3 b}$ and $\mathbf{3 f}$ were reacted concomitantly, the corresponding carboxylative cyclization products $\mathbf{4 b}$ and $\mathbf{4 f}$ were obtained. No cross products $\mathbf{6}$ and $\mathbf{7}$ were detected, which implies that the $\mathrm{N}$ to $\mathrm{C}$ acyl shift occurred intramolecularly, not intermolecularly.

\section{Conclusion}

In summary, we have developed a DBU-promoted carboxylative cyclization of $o$-hydroxy- and $o$-acetamidoacetophenones with carbon dioxide. This methodology provides a convenient access to the biologically important 4-hydroxy- $2 H$-chromen-2ones and 4-hydroxy-2(1H)-quinolinones in moderate to good yields under mild reaction conditions. While there are precedents for the carboxylation of enolates, a practical protocol was developed that relies on in situ cyclization to form thermodynamically stable coumarins. Importantly, the use of an intramolecular in situ trap avoids the problem of decarboxylation during workup. In case of $o$-acetamidoacetophenones, an acyl migration from nitrogen to carbon was observed. The cross experiment showed that the $\mathrm{N}$ to $\mathrm{C}$ acyl shift occurred intramolecularly.

\section{Experimental}

Similarly as described in our previous paper [22], a $20 \mathrm{~mL}$ oven-dried autoclave containing a stirring bar was charged with $o$-hydroxyacetophenone (1) or $o$-acetamidoacetophenone (3) (0.5 mmol), DBU (1.0 mmol for $1,2.0 \mathrm{mmol}$ for 3 ), and $2 \mathrm{~mL}$ dry DMSO. After purging the autoclave with $\mathrm{CO}_{2}$ three times, the sealed autoclave was pressurized to the appropriate pressure with $\mathrm{CO}_{2}$. The reaction mixture was stirred at $80{ }^{\circ} \mathrm{C}$ for $24 \mathrm{~h}$, then the autoclave was cooled to room temperature and the remaining $\mathrm{CO}_{2}$ was vented slowly. Then $n$-BuI $(1.0 \mathrm{mmol}$ for $\mathbf{1})$ or $\mathrm{MeI}(2.0 \mathrm{mmol}$ for 3 ) was added into the autoclave and the reaction mixture was stirred at $80{ }^{\circ} \mathrm{C}$ (for $\mathbf{1}$ ) or at $30^{\circ} \mathrm{C}$ (for 3) for $4 \mathrm{~h}$. The reaction mixture was then diluted with water $(30 \mathrm{~mL})$ and extracted with ethyl acetate $(3 \times 30 \mathrm{~mL})$. The combined organic layers were washed with water and brine, dried over $\mathrm{Na}_{2} \mathrm{SO}_{4}$ and filtered. The solvent was removed under vacuum. The product was isolated by column chromatography on silica gel (hexane/ethyl acetate 2:1).

\section{Supporting Information}

\section{Supporting Information File 1}

Experimental procedures, spectroscopic and analytical data, and copies of NMR spectra of the products.

[http://www.beilstein-journals.org/bjoc/content/ supplementary/1860-5397-11-102-S1.pdf]

\section{Acknowledgements}

This work was supported by the National Natural Science Foundation of China (21172026), the Fundamental Research Funds for the Central Universities (DUT15LAB21), and the Program<smiles>COc1ccc(C(C)=O)c(NC(C)=O)c1</smiles><smiles>COc1ccc2c3c(c(=O)n(C)c2c1)C(=O)CCCO3</smiles>

6<smiles>Cn1c(=O)c2c(c3ccccc31)OCCCC2=O</smiles><smiles>COc1c(C(C)=O)c(=O)n(C)c2ccccc12</smiles>

7

Not detected 
for Changjiang Scholars and Innovative Research Team in University (IRT13008). X.-B. Lu gratefully acknowledges the Chang Jiang Scholars Program (no. T2011056) from Ministry of Education, People's Republic of China.

\section{References}

1. Pratap, R.; Ram, V. J. Chem. Rev. 2014, 114, 10476. doi: $10.1021 /$ cr500075s

See for a review.

2. Holbrook, A. M.; Pereira, J. A.; Labiris, R.; McDonald, H.; Douketis, J. D.; Crowther, M.; Wells, P. S. Arch. Intern. Med. 2005, 165, 1095. doi:10.1001/archinte.165.10.1095

3. Hoeksema, H.; Johnson, J. L.; Hinman, J. W. J. Am. Chem. Soc. 1955, 77, 6710. doi:10.1021/ja01629a129

4. Cullen, J. J.; Hinkhouse, M. M.; Grady, M.; Gaut, A. W.; Liu, J.; Zhang, Y. P.; Weydert, C. J. D.; Domann, F. E.; Oberley, L. W. Cancer Res. 2003, 63, 5513.

5. Jönsson, S.; Andersson, G.; Fex, T.; Fristedt, T.; Hedlund, G.; Jansson, K.; Abramo, L.; Fritzson, I.; Pekarski, O.; Runström, A.; Sandin, H.; Thuvesson, I.; Björk, A. J. Med. Chem. 2004, 47, 2075. doi:10.1021/jm031044w

6. Hack, D.; Chauhan, P.; Deckers, K.; Hermann, G. N.; Mertens, L.; Raabe, G.; Enders, D. Org. Lett. 2014, 16, 5188. doi:10.1021/ol502551u

7. Prousis, K. C.; Tzani, A.; Avlonitis, N.; Calogeropoulou, T.; Detsi, A. J. Heterocycl. Chem. 2013, 50, 1313. doi:10.1002/jhet.1869

8. Ambre, P. K.; Pissurlenkar, R. R. S.; Wavhale, R. D.; Shaikh, M. S.; Khedkar, V. M.; Wan, B.; Franzblau, S. G.; Coutinho, E. C. Med. Chem. Res. 2014, 23, 2564. doi:10.1007/s00044-013-0850-7

9. Sakakura, T.; Choi, J.-C.; Yasuda, H. Chem. Rev. 2007, 107, 2365. doi:10.1021/cr068357u

10. Riduan, S. N.; Zhang, Y. Dalton Trans. 2010, 39, 3347. doi:10.1039/b920163g

11. Huang, K.; Sun, C.-L.; Shi, Z.-J. Chem. Soc. Rev. 2011, 40, 2435. doi:10.1039/c0cs00129e

12. Cokoja, M.; Bruckmeier, C.; Rieger, B.; Herrmann, W. A.; Kühn, F. E. Angew. Chem., Int. Ed. 2011, 50, 8510. doi:10.1002/anie.201102010

13. Zhang, W.; Lü, X. Chin. J. Catal. 2012, 33, 745. doi:10.1016/S1872-2067(11)60390-2

14. Tsuji, Y.; Fujihara, T. Chem. Commun. 2012, 48, 9956. doi:10.1039/c2cc33848c

15. Zhang, L.; Hou, Z. Chem. Sci. 2013, 4, 3395. doi:10.1039/c3sc51070k

16. Aresta, M.; Dibenedetto, A.; Angelini, A. Chem. Rev. 2014, 114, 1709. doi:10.1021/cr4002758

17. Flowers, B. J.; Gautreau-Service, R.; Jessop, P. G. Adv. Synth. Catal. 2008, 350, 2947. doi:10.1002/adsc.200800516

18. Kikuchi, S.; Sekine, K.; Ishida, T.; Yamada, T. Angew. Chem., Int. Ed. 2012, 51, 6989. doi:10.1002/anie.201201399

19. Sekine, K.; Takayanagi, A.; Kikuchi, S.; Yamada, T. Chem. Commun. 2013, 49, 11320. doi:10.1039/c3cc47221c

20. Zhang, W.-Z.; Shi, L.-L.; Liu, C.; Yang, X.-T.; Wang, Y.-B.; Luo, Y.; Lu, X.-B. Org. Chem. Front. 2014, 1, 275. doi:10.1039/c3qo00047h

21. Da Re, P.; Sandri, E. Chem. Ber. 1960, 93, 1085. doi:10.1002/cber.19600930514

22. Guo, C.-X.; Zhang, W.-Z.; Liu, S.; Lu, X.-B. Catal. Sci. Technol. 2014, 4, 1570. doi:10.1039/c3cy00858d

23. Zhang, W.-Z.; Xia, T.; Yang, X.-T.; Lu, X.-B. Chem. Commun. 2015, 51, 6175. doi:10.1039/c5cc01530h
24. Wu, X.-F.; Anbarasan, P.; Neumann, H.; Beller, M. Angew. Chem., Int. Ed. 2010, 49, 9047. doi:10.1002/anie.201006374 See for a review.

25. Zhang, Z.; Fang, S.; Liu, Q.; Zhang, G. J. Org. Chem. 2012, 77, 7665. doi:10.1021/j03010217

26. Strumfs, B.; Hermane, J.; Belyakov, S.; Trapencieris, P. Tetrahedron 2014, 70, 355. doi:10.1016/j.tet.2013.11.052

27. Ameen, D.; Snape, T. J. Synthesis 2015, 47, 141. doi:10.1055/s-0034-1379498

\section{License and Terms}

This is an Open Access article under the terms of the Creative Commons Attribution License

(http://creativecommons.org/licenses/by/2.0), which permits unrestricted use, distribution, and reproduction in any medium, provided the original work is properly cited.

The license is subject to the Beilstein Journal of Organic Chemistry terms and conditions: (http://www.beilstein-journals.org/bjoc)

The definitive version of this article is the electronic one which can be found at: doi:10.3762/bjoc. 11.102 